\title{
CFD analysis of airflow in voids for better cross ventilation in midrise buildings in hot and humid climates.
}

\author{
Nikhil Kumar ${ }^{1}$, Tetsu Kubota ${ }^{2}$, Ronita Bardhan ${ }^{1}$, Yoshihide Tominaga ${ }^{3}$ \\ ${ }^{1}$ Centre for Urban Science and Engineering, Indian Institute of Technology Bombay, 400076, \\ Mumbai, India; \\ ${ }^{2}$ International Development and Cooperation, Hiroshima University, 1-5-1 Kagamiyama, Higashi- \\ Hiroshima, 739-8529 Hiroshima, Japan; \\ ${ }^{3}$ Wind and Fluid Engineering Research Centre, Niigata Institute of Technology, Kashiwazaki, \\ Japan
}

\begin{abstract}
There is an increase in the middle income class in the tropical cities of the global south. Which has lead governments to focus on the provision of sustainable housing stocks. The design of these houses is a concern as they are often designed to maximize occupancy. Based on analysis of existing building design, the standard midrise buildings of Indonesia and Mumbai, India consists of double-loaded buildings to optimize the spaces. In such double-loaded buildings, the occupants living on the leeward side of the building may encounter poor crossventilation. This study aims to determine the optimum void design allowing sufficient cross-ventilation in naturally ventilated multi-story buildings. Computational Fluid Dynamics (CFD) is used to study the ventilation effect of voids with different sizes, windcatcher, and window size. CFD simulations are validated with the help of a Wind Tunnel Experiment (WTE). The results conclude that the provision of a void can increase natural ventilation in the leeward units of the building. The smallest void size showed the highest wind velocities. Provision of windcatcher and bigger-sized window further increased the natural ventilation on the leeward units of the building.
\end{abstract}

\section{Introduction}

The majority of the developing nations are experiencing rapid population growth in urban areas. It is projected that almost half of the population increase from 2017 to 2050 is going to happen in ten developing nations, which include India and Indonesia. The increase in population is seen mainly in the middle-income group, which has risen to $46.8 \%$ of the total in the case of Indonesia. The government is committed to provide low-cost sustainable housing to accommodate the growing urban population.

In the northern hemisphere, one of the primary focus in building design is given on maximizing sunlight during the winter months. Hence south-facing single-loaded buildings are preferred. Meanwhile, in the tropics, an emphasis should be given to better natural ventilation for thermal comfort. Traditionally, houses in Global South had architectural elements including voids that allow sufficient ventilation for thermal comfort while providing for solar shading (e.g., chawls of Mumbai). The rising demand for housing has led government to compromise on the solar design and promote high dense vertical structure with double loaded corridors having minimized ventilation. In such conditions, the occupants living on the leeward side of the buildings generally encounter poor to no cross-ventilation.

Vertical void also known as air well, generally located in the center of midrise buildings, is a passive architecture feature for ventilation and natural lighting (Farea et al., 2015, Kotani et al., 2003). A well-designed void can help to improve the indoor air quality and maintenance of excellent indoor thermal comfort for midrise buildings particularly under hot-humid climates (Hirano et al., 2006; Murakami et al, 2004).

This study aims to reintroduce the voids in the high dense vertical midrise buildings and determine the optimum void size for effective cross-ventilation and indoor thermal comfort under naturally ventilated condition. This paper presents the results of Computational Fluid Dynamics (CFD) simulations on ventilation effect with various void configurations in typical midrise buildings. The results are validated with the help of a wind tunnel experiment conducted at Niigata Institute of technology wind tunnel facility. The novelty of the study lies in reintroducing a traditional building design element, i.e., void, in modern midrise buildings.

\section{Prevailing building design in Indonesia and Mumbai.}

A study is conducted to reckon the building design of midrise multi-unit buildings existing in Indonesia and Mumbai. 168 housing site are studied for the cities of Mumbai (102), Jabodetabek (40), Surabaya (15) and Bandug (11) with around 794 building units. Data for Mumbai was collected from secondary sources and government websites i.e., Maharashtra Housing and Area Development Authority. (MHADA), Maharashtra Real Estate Regulatory Authority (MRERA).

The architectural elements considered for the study are:

- Number of Cores: It refers to the number of movement core (Stairs and lift combined to make a core) in the building. More than 80 percent of the buildings have a single core all together.

- Corridor type: It refers to the location of units around the corridor, double-loaded corridor is the most common type with over 80 percent of the buildings having it. 
- Building shape: 'I' shaped buildings are the most common. 30 percent of the buildings are I shaped.

- Building floors: The average number of floors in Mumbai is 12.38 as for Indonesia it is 21.32.

- Location of balcony: In case of Mumbai, 75 percent of the units don't have a balcony where as it is compulsory to provide one in Indonesia.

- Location of toilet: Toilets are located on the exterior wall of the units for buildings in Mumbai. In Indonesian case, they are located around the interior wall (corridor side).

- Size of units: Based on the analysis the average size for one bedroom, two bedrooms, three bedrooms unit are $25.3 \mathrm{~m}^{2}, 34.4 \mathrm{~m}^{2}$ and $44.9 \mathrm{~m}^{2}$ for Indonesia and in case of Mumbai, it is 19 $\mathrm{m}^{2}, 33 \mathrm{~m}^{2}$, and $56 \mathrm{~m}^{2}$.

Figure 1 shows the typical plan of a building in Indonesia (Type A) and that of a building in Mumbai (Type B). Both the building designs were studied for their natural ventilation performance with the help of Wind Tunnel and CFD simulations. The results showed satisfactory natural ventilation on the windward side of the building, but on the leeward side, the recorded wind velocities inside the units was approximately zero in both the types, hence it can be said there is no natural ventilation. Thereby suggesting a need for a better building design for natural ventilation for the leeward side. A new building design Type $\mathrm{C}$ is introduced with a void in between the windward and leeward side is studied with different configurations to suggest a better building design as shown in Figure 4.

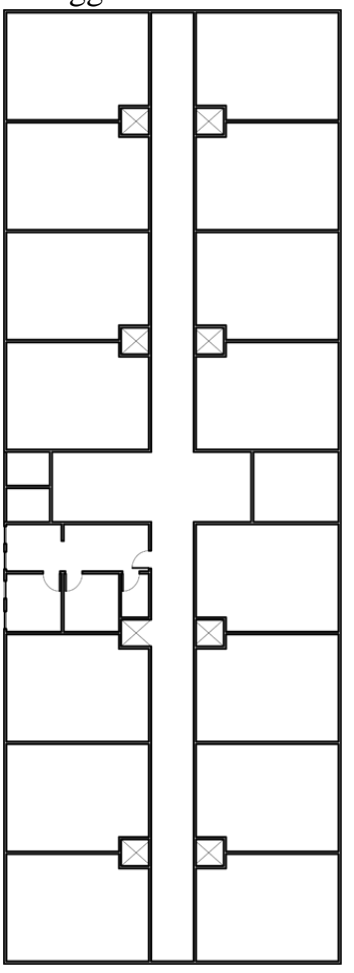

Type A (Indonesia)



Type B (Mumbai)
Figure 1 Typical plan of multi storey buildings in Indonesia (Type A) and Mumbai (Type B).

\section{Methods}

Experimental description: In this study, a wind tunnel is used to measure wind velocity in the center of the units using a constant temperature anemometry (CTA) module (Dantec Dynamics; 90C10) for validating the simulated results. The experiments were carried in atmospheric boundary layer wind tunnel at Niigata Institute of Technology (S. Akabayashi; A. Mochida; Y. Tominaga; M. Yoshida; J. Sakaguchi, 1996; Tominaga \& Blocken, 2015). The wind tunnel boundary layer has a test section of $13 \mathrm{~m}$, working cross section of $1.8 \mathrm{~m}$ height and $1.8 \mathrm{~m}$ width. Figure 2 shows the experimental setup for wind speed measurements. The model is made at a scale of 1:75 from $2 \mathrm{~mm}$ acrylic sheet. The wind tunnel is setup using a combination of wooden blocks and surface roughness to create a wind profile representative of the neutral atmospheric boundary layer. Figure 3 shows the normalized vertical profile of mean velocity $\overline{\mathrm{u}}$ and

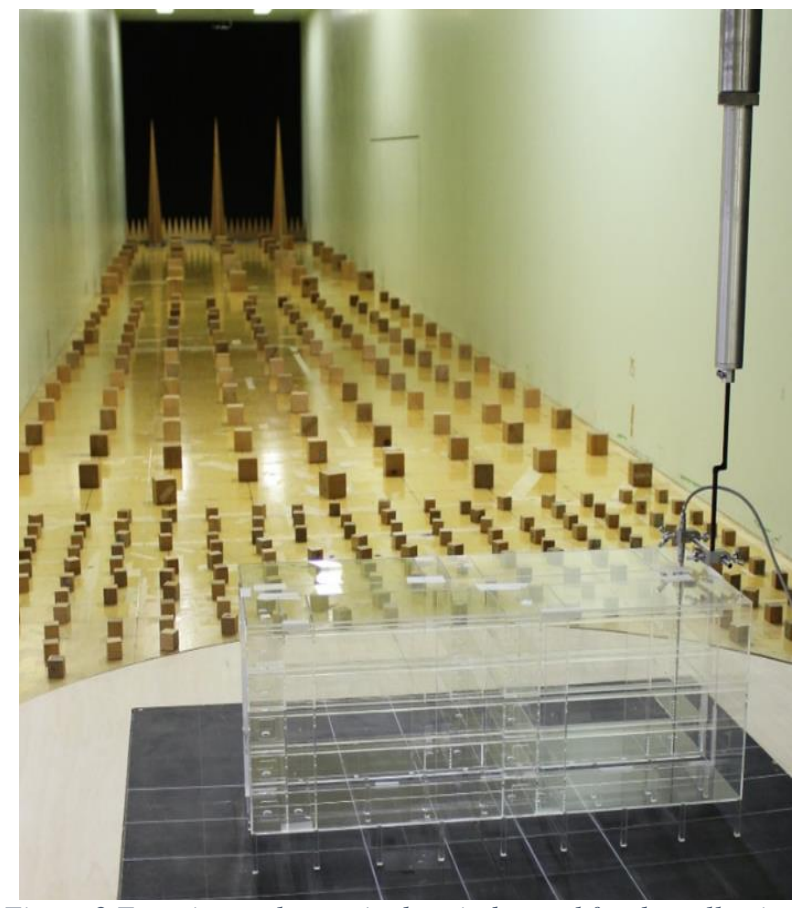

Figure 2 Experimental setup in the wind tunnel for the collection of wind velocity.
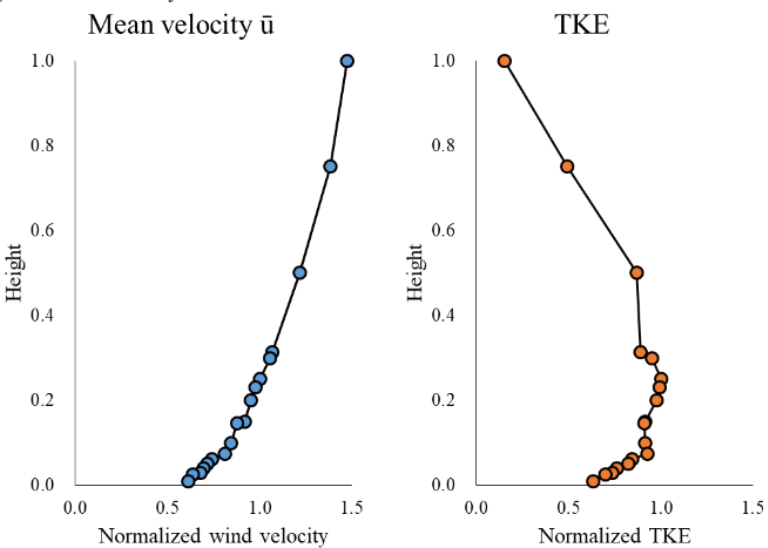

Figure 3 Incident profiles of mean velocity $\bar{u}$ and turbulent kinetic energy $k$ 
turbulent kinetic energy $\mathrm{k}$ for the incident flow measured at the center of the wind tunnel cross-section. Normalization is done with the reference velocity at the building height $252 \mathrm{~mm}$ which is $3.95 \mathrm{~ms}^{-1}$ and $0.367 \mathrm{~m}^{2} \mathrm{~s}^{-}$ 2 for mean velocity and turbulent kinetic energy respectively.

Model description: To study the most optimized void configuration concerning natural ventilation, the present study were examined in increasing the performance of voids and wind-catcher to increase natural ventilation in the leeward units of buildings. The standard building design, i.e., a six-floor building with pilotis on the first floor, was used for the simulations. It is a double-loaded building with an internal void space in the middle of the building. The unit size is $45 \mathrm{~m}^{2}$, and the floor height is $3 \mathrm{~m}$. All the units have an open ventilator shaft of

Table 1CFD simulation cases
$0.8 \mathrm{mx} 2 \mathrm{~m}$ at the height of $2.2 \mathrm{~m}$ which opens towards the void space. Figure 4 shows the building 3D, Plan, and Section used for CFD. A total of 27 cases are considered for the CFD simulation with a varying in void width (small $1.2 \mathrm{~m}$, Medium $3 \mathrm{~m}$, large $6 \mathrm{~m}$ ) and window size (no window, WWR 15\%, WWR 25\%) as shown in Table1.

The commercial software ANSYS Fluent 16.2 was used for simulating the wind speed and pressure. A scaled building model of 1:75 was prepared for CFD simulations. The scale 1:75 was chosen to keep parity with the model used for the wind tunnel experiments.

The computational domain was set according to the best practices guidelines for CFD (Joerg Franke, 2006; Jorg Franke, Hellsten, Schlünzen, \& Carissimo, 2007; Tominaga et al., 2008).

\begin{tabular}{lllllllllllllllllllllllllllllll}
\hline Cases & 1 & 2 & 3 & 4 & 5 & 6 & 7 & 8 & 9 & 10 & 11 & 12 & 1314 & 15 & 16 & 17 & 18 & 19 & 20 & 21 & 22 & 23 & 24 & 25 & 26 & 27 \\
Void Size & S & M & L & S & M & L & S & M & L & S & S & M & M L L L S & S & M & M & L & L & S & S & M & M & L & L \\
Catcher Size & N N N & N & M & M & M & L & L & L & N & N & N & N N N N M & M & M & M & M & M & L & L & L & L & L & L \\
Window size & N N N & N & N & N & N & N & N & N & M & L & M L L M L & M & L & M & L & M & L & M & L & M & L & M & L
\end{tabular}

Void (S: Small void, M: Medium void, L: Large void) Windcatcher (N: No windcatcher, M: Half-size windcatcher, L: Large size windcatcher) Window (N: No window, M: $15 \%$ WWR, L: 25\% WWR).
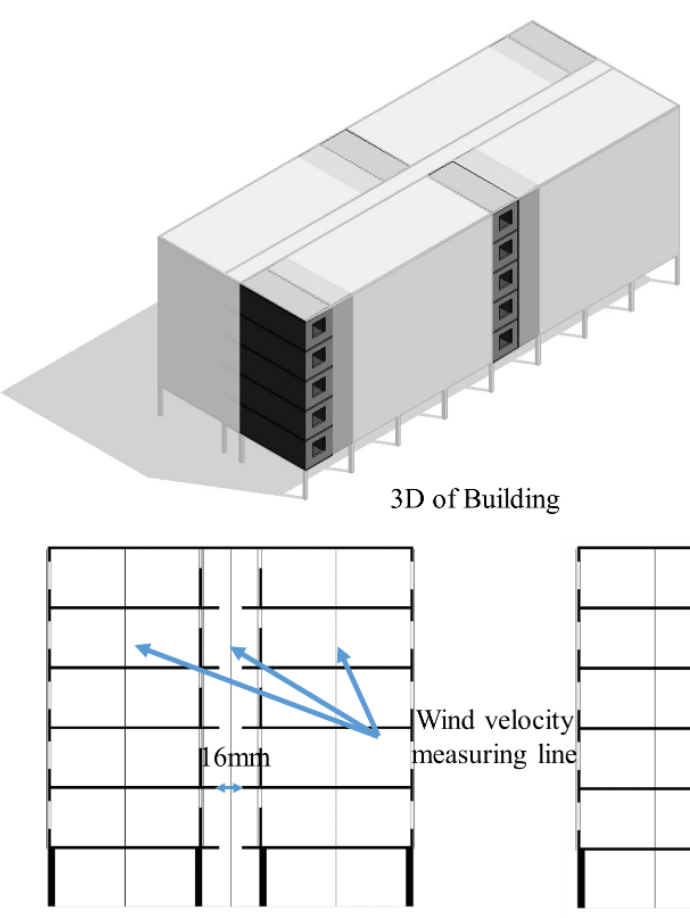

Small void section

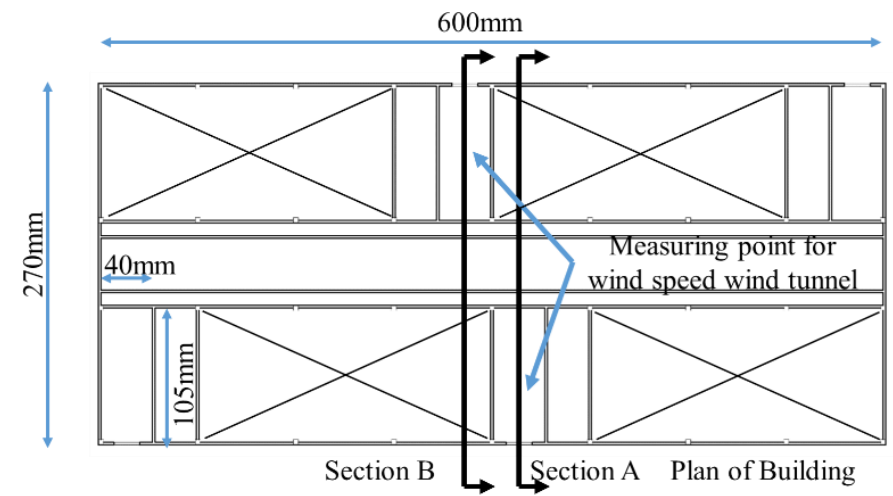

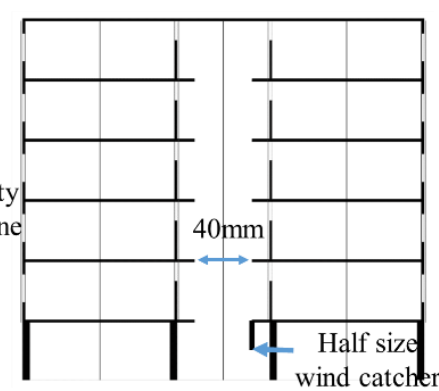

Medium void section

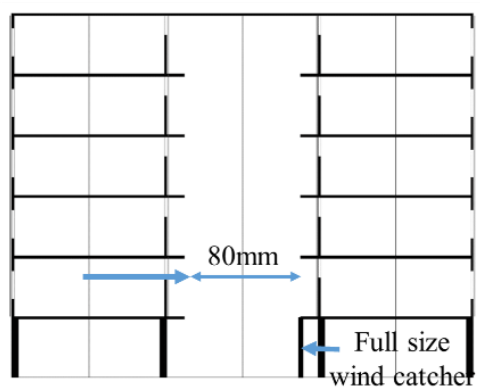

Large Void section

Figure 4 3D model, plan, and section of the model used for CFD simulations and wind tunnel experiments.

Flow domain: The size of (Length $4.8 \mathrm{~m}$, Breath $3 \mathrm{~m}$, Height $1.5 \mathrm{~m}) 5 \mathrm{H}$ from the inlet to the building wall on the windward side, $15 \mathrm{H}$ from the leeward wall to the outlet, $5 \mathrm{H}$ on both sides of the building and $5 \mathrm{H}$ from the roof of the building to the top of the domain was fixed (Where $\mathrm{H}$ refers to the building height) the flow domain was discretized using tetrahedron grids with a high resolution near the building area. An inflation layer is added to the 
bottom layer of the domain. The maximum grid size for the flow area is set at $30 \mathrm{~mm}$ and $2.5 \mathrm{~mm}$ for the building with a growth rate of $120 \%$ in all directions.

Boundary condition: The inlet wind profile is generated with reference to the wind tunnel at Niigata Institute of Technology(Kubota, Miura, Tominaga, \& Mochida, 2008). The one fourth power law wind profile is generated for a referenced velocity of $3.95 \mathrm{~ms}^{-1}$ at the building height of $.252 \mathrm{~m}$. turbulent kinetic energy profile is obtained from the wind tunnel as shown in Figure 3. $\varepsilon$ profiles are given by assuming local equilibrium of the production term for $\mathrm{k}$ equation.

Turbulent modeling: The current study employed the standard $\mathrm{k} \varepsilon$ model. A convergence of scaled residuals down to $10^{-5}$ is employed.

\section{Validation}

The experimental data of wind velocity at the center of the living units as shown in Figure 4 were collected for a total of twelve cases with variation in void, window, and windcatcher sizes eight points were measured in each of the cases (Mid points on Ground-floor, $1^{\text {st }}$ floor, $3^{\text {rd }}$ floor, and $5^{\text {th }}$ floor on the windward and leeward side of the building). A total of 12 cases with 8 points in each resulted in 96 points for validation. The model used for validation was the same as that used in the wind tunnel experiment. The comparison between the measured and simulated wind velocity for all 96 points is made using the two indicative parameters i.e. mean bias error (MBE), and cumulative variation of root mean square (CVRMSE) which are calculated by

$$
\begin{aligned}
& M B E=\frac{1}{n} \sum_{i=1}^{n}\left(\frac{S_{i}-M_{i}}{M_{i}}\right) \\
& \text { CVRMSE }=\sqrt{\frac{1}{n} \sum_{i=1}^{n}\left(\frac{S_{i}-M_{i}}{M_{i}}\right)^{2}}
\end{aligned}
$$

Where $\mathrm{M}_{\mathrm{i}}$ and $\mathrm{S}_{\mathrm{i}}$ are the measured and simulated results respectively. The MBEs in all the cases came below $4 \%$ and all the RMSEs were less than 7\% According to ASHRAE criteria (Gillespie et al., 2002) the model is validated if MBE is less than $10 \%$ and RMSE is below $30 \%$. The results of the measured and simulated wind velocity were in clear agreement.

\section{Results and discussions}

Studying natural ventilation performance of a building design needs detailed airflow information in and around the building. The ventilation rates can be determined based on the wind velocities at inlets and outlets of the units. This section presents the results of parametric CFD simulations done by changing the void size, window size and introduction of windcatcher.

Wind velocity: Wind velocity data from CFD simulations was measured at the middle of the windward units, leeward units and center of the void. Wind Speed Ratio (WSR) was calculated as the ratio between wind velocity at a point $\left(\mathrm{U}_{\mathrm{h}}\right)_{\mathrm{I}}$ and the reference point placed at the height of the building $U_{r}$. Cases 1-9 emphasises on the wind velocity in the void, the average WSR in the centre of the void for cases 7-9, with the full size windcatcher is the highest compared to the cases 4-6 with a half size windcatcher and the lowest WSR is seen in cases 1-3 with no windcatcher. Case 7 which has a small void and full size windcatcher has the largest average WSR in the void area. In cases 10-27 the wind velocity is measured in the building units. The average WSR in the centre of the unit is calculated for windward and leeward units. Table 2 shows the wind speed ratio from cases 10-27 for units on each floor.

\begin{tabular}{|c|c|c|c|c|c|c|c|c|c|c|c|c|c|c|c|c|c|c|}
\hline \multicolumn{19}{|c|}{ Windward units } \\
\hline 6-F & 0.17 & 0.16 & 0.18 & 0.16 & 0.18 & 0.16 & 0.14 & 0.12 & 0.14 & 0.13 & 0.15 & 0.14 & 0.10 & 0.09 & 0.10 & 0.09 & 0.11 & 0.10 \\
\hline 5-F & 0.16 & 0.15 & 0.16 & 0.15 & 0.16 & 0.15 & 0.12 & 0.12 & 0.13 & 0.12 & 0.13 & 0.12 & 0.09 & 0.09 & 0.08 & 0.09 & 0.10 & 0.10 \\
\hline 4-F & 0.16 & 0.14 & 0.16 & 0.14 & 0.16 & 0.14 & 0.12 & 0.11 & 0.12 & 0.11 & 0.13 & 0.12 & 0.08 & 0.08 & 0.08 & 0.08 & 0.09 & 0.09 \\
\hline 3-F & 0.17 & 0.15 & 0.17 & 0.15 & 0.17 & 0.15 & 0.13 & 0.11 & 0.14 & 0.12 & 0.14 & 0.12 & 0.08 & 0.08 & 0.09 & 0.08 & 0.10 & 0.09 \\
\hline 2-F & 0.17 & 0.15 & 0.17 & 0.15 & 0.17 & 0.15 & 0.13 & 0.12 & 0.13 & 0.12 & 0.14 & 0.13 & 0.08 & 0.08 & 0.08 & 0.08 & 0.10 & 0.09 \\
\hline 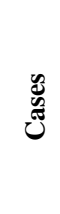 & 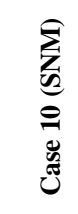 & 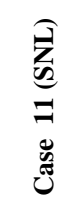 &  & 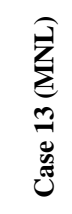 & 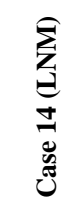 &  & 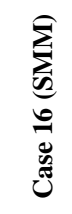 & 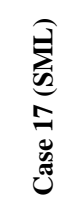 & 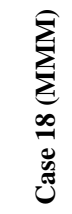 & 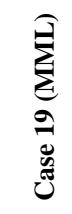 & 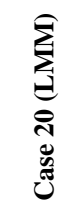 & 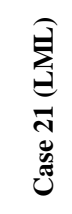 &  & 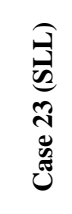 &  & 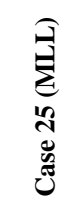 & 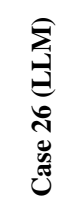 & 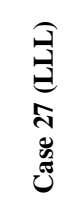 \\
\hline 6-F & 0.02 & 0.03 & 0.01 & 0.01 & 0.01 & 0.01 & 0.12 & 0.18 & 0.11 & 0.13 & 0.12 & 0.13 & 0.15 & 0.20 & 0.18 & 0.24 & 0.15 & 0.21 \\
\hline $5-F$ & 0.02 & 0.03 & 0.00 & 0.01 & 0.01 & 0.01 & 0.15 & 0.20 & 0.07 & 0.06 & 0.03 & 0.05 & 0.18 & 0.24 & 0.19 & 0.25 & 0.16 & 0.21 \\
\hline 4-F & 0.01 & 0.02 & 0.01 & 0.01 & 0.01 & 0.01 & 0.15 & 0.20 & 0.11 & 0.11 & 0.03 & 0.05 & 0.19 & 0.24 & 0.18 & 0.24 & 0.15 & 0.16 \\
\hline $3-F$ & 0.01 & 0.02 & 0.01 & 0.01 & 0.01 & 0.00 & 0.14 & 0.19 & 0.04 & 0.05 & 0.08 & 0.05 & 0.17 & 0.22 & 0.17 & 0.20 & 0.16 & 0.20 \\
\hline $2-F$ & 0.02 & 0.02 & 0.01 & 0.01 & 0.03 & 0.04 & 0.13 & 0.18 & 0.12 & 0.15 & 0.12 & 0.16 & 0.18 & 0.22 & 0.17 & 0.23 & 0.15 & 0.21 \\
\hline
\end{tabular}

Table 2 Wind speed ratio of windward and leeward units for all the cases. 
Figure 5 shows the wind velocity profile in the $1^{\text {st }}$ floor and $5^{\text {th }}$ floor units for the Case 11 (SNL) and Case 23 (SLL). Case 11 has the highest wind velocity for the windward side and Case 23 for the leeward side.

The WSR in windward units remains constant with the increase in the void size as seen in Cases 10, 12 and 14. Increasing the window size decreases the WSR for the windward units for all cases. Adding windcatcher at the first floor decreases the WSR on the windward side. Increasing the size of windcatcher further decreases the WSR. The minimum WSR for the windward units can be seen in Cases 23 and 25. For a single building the WSR on the windward side is smaller in the $3^{\text {rd }}$ floor (middle units), bigger on the $1^{\text {st }}$ and $5^{\text {th }}$ floors (lower and upper floors).

In case of leeward units the smaller voids have better WSR. Increase in window size resulted in increased WSR. Addition of windcatcher further increases the WSR as in Cases 22-27.WSR is highest in the $3^{\text {rd }}$ floor (mid units) compared to the $5^{\text {th }}$ and $1^{\text {st }}$ floors (upper and lower units).

Flow rates: Air flow rates for the units were calculated using the formula $\mathrm{U}_{\text {opening }} * \mathrm{~A}$ where $\mathrm{U}_{\text {opening }}$ is the area averaged velocity on window plane, and $\mathrm{A}$ is the geometric area of the opening. The unit of flow rate is $\mathrm{m}^{3} \mathrm{~s}^{-}$ ${ }^{1}$.The flow rates for Cases 10-27 are calculated and normalized using $2.6 \mathrm{~m}^{3} \mathrm{~s}^{-1}$, which is the flow rate of middle unit on the windward side of Case 19 (MML) as

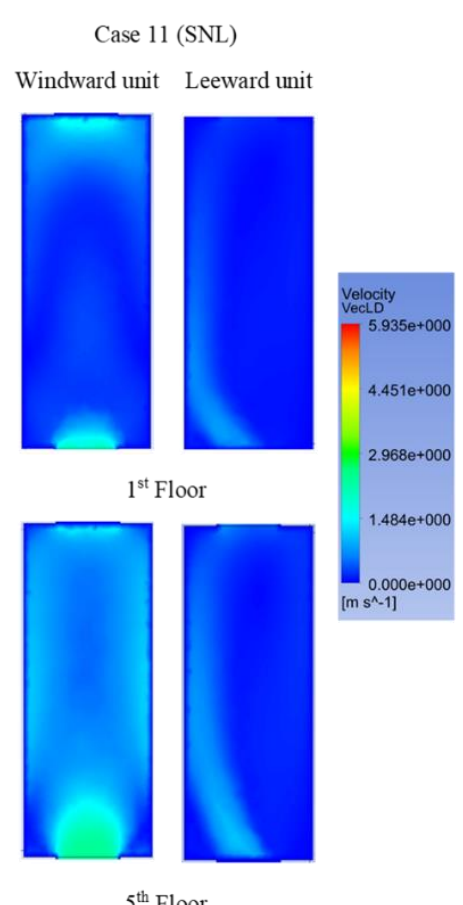

Case 23 (SLL)

Windward unit Leeward unit

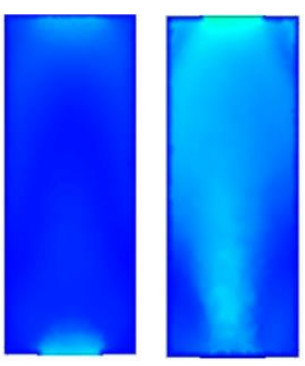

$1^{\text {st }}$ Floor

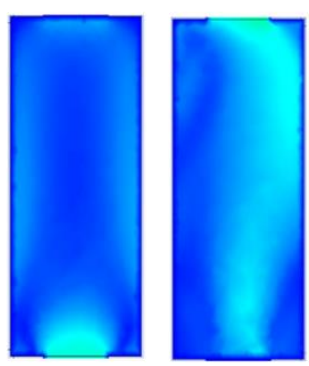

$5^{\text {th }}$ Floor

Figure 5 Wind velocity in the $1^{\text {st }}$ and $5^{\text {th }}$ floor units of case 11 and 23 .

the reference case. Table 3 shows the normalized flow rates of all the cases.

Table 3 Flow rates in the windward and leeward units for all the cases.

\begin{tabular}{|c|c|c|c|c|c|c|c|c|c|c|c|c|c|c|c|c|c|c|}
\hline \multicolumn{19}{|c|}{ Windward units } \\
\hline 6-F & 0.77 & 1.12 & 0.81 & 1.15 & 0.81 & 1.15 & 0.62 & 0.92 & 0.65 & 0.96 & 0.65 & 1.35 & 0.42 & 0.65 & 0.42 & 0.65 & 0.46 & 0.73 \\
\hline $5-F$ & 0.88 & 1.23 & 0.88 & 1.23 & 0.88 & 1.23 & 0.69 & 1.00 & 0.73 & 1.04 & 0.73 & 1.50 & 0.54 & 0.77 & 0.50 & 0.73 & 0.58 & 0.81 \\
\hline $4-F$ & 0.85 & 1.19 & 0.88 & 1.19 & 0.88 & 1.19 & 0.69 & 0.96 & 0.73 & 1.00 & 0.73 & 1.46 & 0.50 & 0.73 & 0.50 & 0.73 & 0.58 & 0.81 \\
\hline 3-F & 0.81 & 1.12 & 0.81 & 1.12 & 0.81 & 1.12 & 0.62 & 0.88 & 0.65 & 0.92 & 0.69 & 1.35 & 0.42 & 0.65 & 0.42 & 0.62 & 0.50 & 0.73 \\
\hline $2-F$ & 0.69 & 1.00 & 0.69 & 1.04 & 0.69 & 1.04 & 0.54 & 0.77 & 0.58 & 0.85 & 0.62 & 1.23 & 0.38 & 0.54 & 0.38 & 0.58 & 0.42 & 0.62 \\
\hline שֶ & 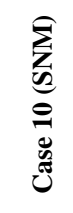 & 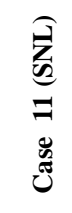 & 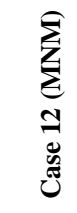 & 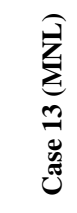 & 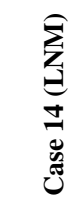 & 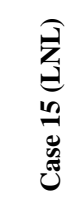 & 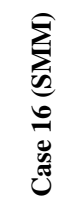 & 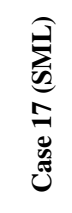 & 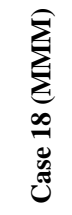 & 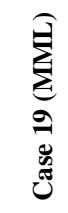 & 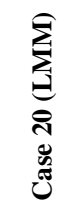 & 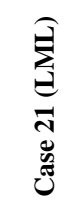 & 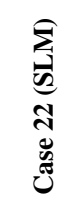 & 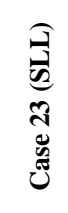 & 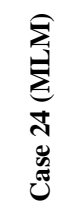 & 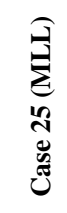 & 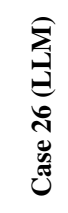 & 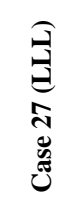 \\
\hline 6-F & 0.15 & 0.27 & 0.00 & 0.04 & -0.04 & 0.00 & 0.58 & 0.77 & 0.54 & 0.73 & 0.50 & 0.92 & 0.77 & 1.00 & 0.77 & 1.04 & 0.73 & 0.96 \\
\hline $5-F$ & 0.12 & 0.19 & -0.04 & 0.00 & -0.08 & -0.04 & 0.58 & 0.73 & 0.54 & 0.69 & 0.46 & 0.81 & 0.81 & 1.04 & 0.81 & 1.04 & 0.73 & 0.96 \\
\hline $4-F$ & 0.04 & 0.15 & -0.08 & -0.04 & -0.12 & -0.08 & 0.58 & 0.73 & 0.54 & 0.69 & 0.46 & 0.77 & 0.81 & 1.04 & 0.81 & 1.04 & 0.73 & 0.96 \\
\hline 3-F & 0.08 & 0.12 & -0.04 & 0.00 & -0.08 & -0.04 & 0.62 & 0.77 & 0.54 & 0.65 & 0.50 & 0.88 & 0.77 & 1.00 & 0.77 & 1.00 & 0.73 & 0.92 \\
\hline $2-F$ & 0.12 & 0.15 & 0.04 & 0.08 & 0.08 & 0.15 & 0.58 & 0.73 & 0.54 & 0.65 & 0.50 & 0.96 & 0.77 & 0.96 & 0.73 & 0.96 & 0.69 & 0.92 \\
\hline
\end{tabular}

In case of windward units the flow rate is high in cases 10-21. Increase in window size increased the flow rates. Addition of windcatcher reduced the flow rates with case 21 (LML) as an exception.
In case of leeward units, the existence of a void or the increase in void size does not impact the flow rates drastically. Cases 12-14 show negative flow rate i.e. direction of flow is opposite to the wind direction. Flow 


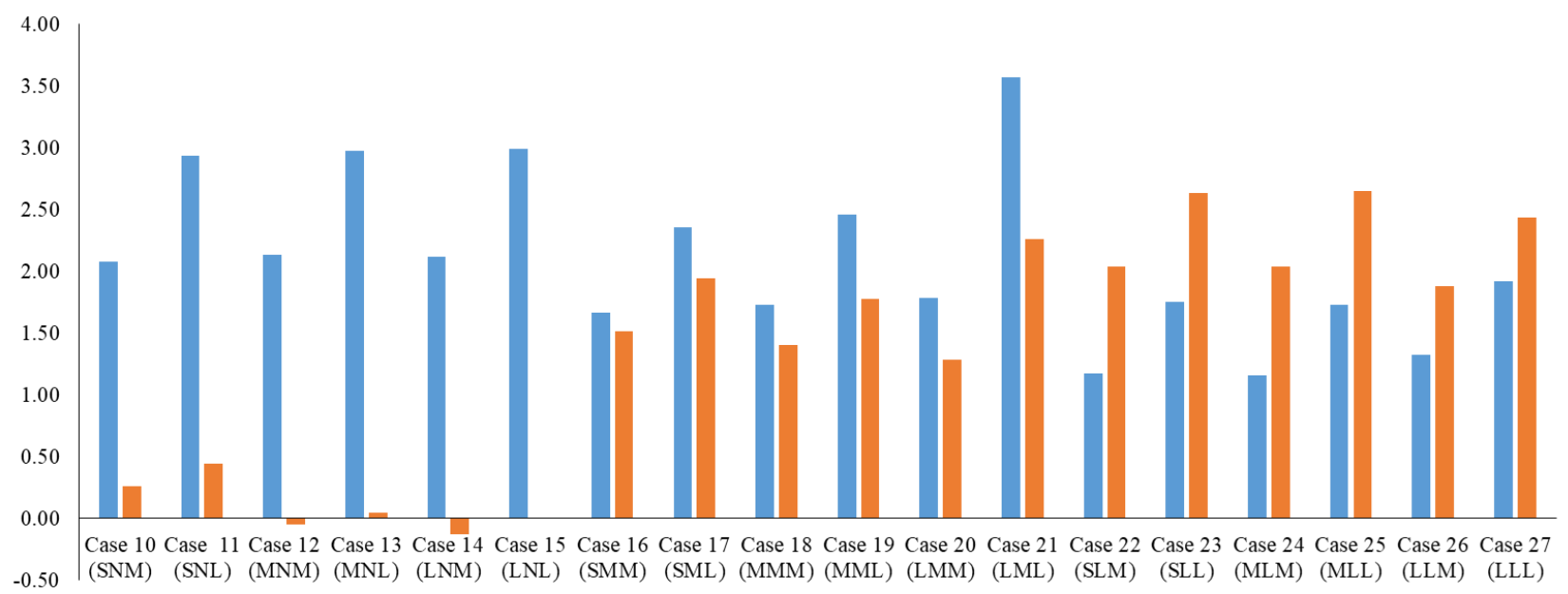

Figure 6 Average per unit flow rate for the cases.

rates drastically improved with the addition of windcatcher.

In the case of windward units, the middle floors $\left(4^{\text {th }}\right.$ and $5^{\text {th }}$ ) have higher flow rates, the $2^{\text {nd }}$ floor has the lowest flow rate compared to the other floors. Deductively, the flow rate gradually increased from lower to middle floors and decreased as it reached top floor in shape of a ' $D$ '. In the case of leeward units, the $2^{\text {nd }}$ and $6^{\text {th }}$ floor have higher flow rates compared to the middle units. The flow rate gradually decreases from bottom to middle increasing back again before reaching the top floor in shape of a ' $\mathrm{C}$ ' though the flow rate differences are very marginal across the floors of the building. Case 15 (LNL)

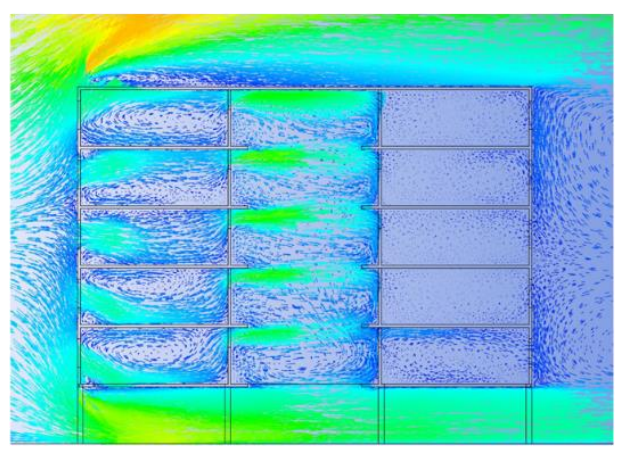

Case 23 (SLL)

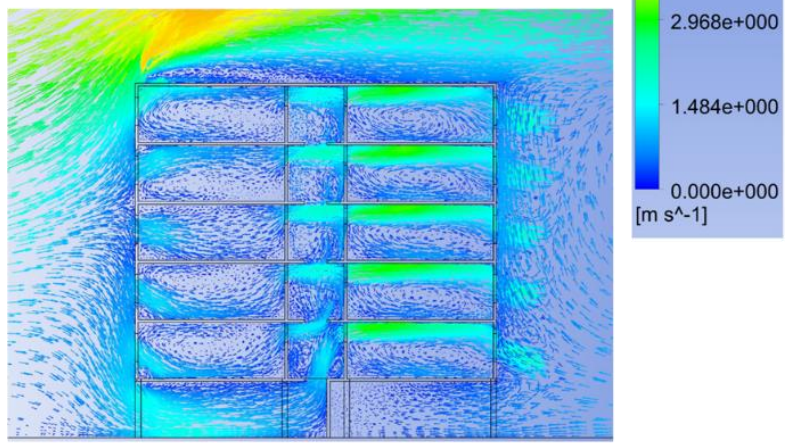

Figure 7 wind velocity in case 15 and case 23 with minimum and maximum flow rates on the leeward side respectively.
Figure 6 shows the per unit average flow rates of all all the cases. Cases 17, 19 and 21 have good flow rates on the windward and the leeward side.

Figure 7 shows Case 15 (LNL) with the best windward flow and negative or zero leeward flow i.e. wind is moving opposite to the wind direction. Case 23 (SLL) shows the best leeward flow in all the cases.

\section{Summary and conclusion}

A total of 27 building design options were studied with the help of CFD and wind tunnel experiments to suggest measures for increasing natural ventilation performance of the building prioritizing its leeward side.

The results can be summarized as:

- Introducing a void in the building design increased the air flow and wind speed ratio in the leeward units. Small void of $1.2 \mathrm{~m}$ is effective than mid and larger voids.

- Increasing the size of the windows was found to be directly proportional to the increase in the air flow rates in the units.

- Use of windcatcher at the pilotis level increased the flow rates in the leeward units while decreasing that on the windward units. Increasing the windcatcher size increased the flow rates on the leeward side and further decreased the flow rates on the windward side. Thus it can be concluded that the use of void can help in increasing natural ventilation in the building. Small size void with $25 \%$ WWR and half-size windcatcher effectively placed could lead to better natural ventilation on both the windward and leeward units equally. Furthermore, there is a need to study the airflow patterns in a void with the change in wind direction and for high rise (20 to 40 floors) to produce much conclusive evidence on better naturally ventilated building design for the tropics. 


\section{Acknowledgment}

We want to thank the supports from YKK AP Corporation. In particular, special thanks are due to Mr. Inoue and Mr. Morita.

\section{References}

Farea, T. G., Ossen, D. R., Alkaff, S., \& Kotani, H. (2015). CFD modeling for natural ventilation in a light well connected to outdoor through horizontal voids. Energy and Buildings, 86, 502-513. https://doi.org/10.1016/j.enbuild.2014.10.030

Franke, J. (2006). Recommendations of the COST action $\mathrm{C} 14$ on the use of CFD in predicting pedestrian wind environment. The Fourth International Symposium on Computational Wind Engineering, 529-532.

Franke, J., Hellsten, A., Schlünzen, H., \& Carissimo, B. (2007). Best practice guideline for the CFD simulation of flows in the urban environment. COST action (Vol. 44). Retrieved from http://cat.inist.fr/?aModele $=$ afficheN\&cpsidt=2389 2111\%5Cnhttp://scholar.google.com/scholar?hl=e $\mathrm{n} \& b \operatorname{tnG}=$ Search\&q=intitle:Best + practice+guidelin e+for+the+CFD+simulation+of+flows+in+the+urb an+environment\#0

Gillespie, K. L., Cowan, J. D., Frazell, C. W., Haberl, J. S., Heinemeier, K. H., Kummer, J. P., ... Montgomery, R. D. (2002). Measurement of Energy and Demand Savings, 8400 .

Hirano, T., Kato, S., Murakami, S., Ikaga, T., \& Shiraishi, Y. (2006). A study on a porous residential building model in hot and humid regions: Part 1 - The natural ventilation performance and the cooling load reduction effect of the building model. Building and Environment, 41(1), 21-32. https://doi.org/10.1016/j.buildenv.2005.01.018
Kotani, H., Satoh, R., \& Yamanaka, T. (2003). Natural ventilation of light well in high-rise apartment building. Energy and Buildings, 35(4), 427-434. https://doi.org/10.1016/S0378-7788(02)00166-4

Kubota, T., Miura, M., Tominaga, Y., \& Mochida, A. (2008). Wind tunnel tests on the relationship between building density and pedestrian-level wind velocity: Development of guidelines for realizing acceptable wind environment in residential neighborhoods. Building and Environment, 43(10), 1699-1708. https://doi.org/10.1016/j.buildenv.2007.10.015

Murakami, S., Kato, S., Ooka, R., \& Shiraishi, Y. (2004). Design of a porous-type residential building model with low environmental load in hot and humid Asia. Energy and Buildings, 36(12), 1181-1189. https://doi.org/10.1016/j.enbuild.2003.08.001

S. Akabayashi; A. Mochida; Y. Tominaga; M. Yoshida; J. Sakaguchi. (1996). Performance of New Wind Tunnel of Niigata Institute of Technology. JWE. Niigata: JWE 1996.

Tominaga, Y., \& Blocken, B. (2015). Wind tunnel experiments on cross-ventilation fl ow of a generic building with contaminant dispersion in unsheltered and sheltered conditions. Building and Environment, $92, \quad 452-461$. https://doi.org/10.1016/j.buildenv.2015.05.026

Tominaga, Y., Mochida, A., Yoshie, R., Kataoka, H., Nozu, T., Yoshikawa, M., \& Shirasawa, T. (2008). AIJ guidelines for practical applications of CFD to pedestrian wind environment around buildings. Journal of Wind Engineering and Industrial Aerodynamics, 96(10-11), 1749-1761. https://doi.org/10.1016/j.jweia.2008.02.058 